\title{
Influence of air pollution exposure on adolescents' objectively-measured physical activity and sedentary behavior
}

\author{
Influência da poluição do ar em adolescentes avaliando \\ objetivamente a atividade física e o comportamento sedentário
}

Jesús Viciana (https://orcid.org/0000-0002-5424-118X) ${ }^{1}$

Daniel Mayorga-Vega (http://orcid.org/0000-0002-4494-4113) ${ }^{1}$

Maribel Parra-Saldías (https://orcid.org/0000-0001-5488-9878) ${ }^{2}$

${ }^{1}$ Departamento de Educación Física y Deportiva, Universidad de Granada. Avda. del Hospicio s/n. 18071 Granada Andalusia Espanha. jviciana@ugr.es

${ }^{2}$ Observatorio del Deporte,

Universidad de Los Lagos.

Santiago de Chile Chile.

\begin{abstract}
Although regular physical activity is recommended for health, highly contaminated air exposure acts to the detriment of the benefits produced in individuals. The purpose of the present study was to compare the accelerometer-measured physical activity and sedentary behavior during the whole day, in-school time, out-of-school time, and school breaks between highly contaminated air days and non-highly contaminated air days in Chilean adolescents. Nineteen adolescents from Santiago of Chile were assessed by a GT3X accelerometer. The vertical axis and steps per minute for the whole day, and both of these variables together with the percentage of time of moderate-to-vigorous physical activity level in the out-of-school time period were higher in highly contaminated air days than in non-highly contaminated air days ( $p<0.05$; with effect sizes from $r=0.36$ to $r$ $=0.46)$. Results for sedentary behavior were similar in both conditions for every period of time analyzed. These results allow us to conclude the lack of awareness of the participants in this research regarding the health repercussions in relation to the physical activity performed during air pollution exposure. Some strategies in order to improve the Chilean adolescents' physical activity and sedentary behavior are suggested and discussed.
\end{abstract}

Key words Smog, School recess, Leisure time, Environment
Resumo Embora a atividade fisica regular seja recomendada para saúde, a exposição de indivíduos ao ar altamente contaminado pode levar a perda dos benefícios produzidos. O propósito do presente estudo foi comparar o nível de atividade fisica e o comportamento sedentário durante $e$ fora das aulas escolares, e nos recessos escolares entre dias altamente contaminados e dias não contaminados em adolescentes chilenos. Dezenove adolescentes de Santiago foram avaliados por um acelerômetro GT3X. O eixo vertical e os passos por minuto durante um dia inteiro, e as duas variáveis assim como a porcentagem de tempo de atividade fisica moderada a vigorosa no período do tempo fora da escola foi superior em dias altamente contaminados do que em dias não altamente contaminados ( $p<0.05 ; r=0.36$ a $r=0.46)$. O resultado do comportamento sedentário foi similar em ambas as condições para cada periodo do tempo analisado. Esses resultados permitem concluir que a falta de consciência dos participantes nessa pesquisa relativa à repercussão na saúde com relação a atividade física executado durante exposição da poluição atmosférica. Algumas estratégias a fim de melhorar o nivel de atividade fisica de adolescentes chilenos e comportamentos sedentários são sugeridas e discutidas.

Palavras-chave Poluição, Recesso escolar, Tempo livre, Meio ambiente 


\section{Introduction}

It is well known that the regular practice of physical activity (PA) is crucial for obtaining health benefits ${ }^{1}$. Unfortunately, the practice of PA does not achieve the daily recommendations of 60 minutes of moderate-to-vigorous PA a day ${ }^{2}$ for the majority of the population ${ }^{3}$, while the total sedentary time is increasing in all age groups. Sedentary behavior in the present study referred to any waking behavior with a low energy expenditure (i.e., $\leq 1.5$ METs, being sitting or in a reclined posture) and not as the lack of $\mathrm{PA}^{5}$. This problem is especially worrisome in adolescents ${ }^{6}$, where the decrease of $\mathrm{PA}$ in societies all over the world has been verified ${ }^{7}$, and the long-term consequences entail, among other things, a drop in PA and the loss of its benefits during adulthood ${ }^{1}$. Due to this, a considerable number of studies have been carried out centered in measuring the performed habitual PA in children and adolescents, focusing on three main contexts: complete $\mathrm{day}^{3}$, school time ${ }^{8}$, and out of school or leisure times.

Although the regular practice of PA is recommended for increasing the general health of individuals ${ }^{10-12}$, it is important to denote that not all conditions are optimal for this recommendation. For instance, the term "smog", referring to air pollution, describes a mixture of emissions (e.g., industrial and vehicle pollutants, open burning, or heating due to human activities) with dust and water vapor under specific climate conditions, which affects the relationship between the practice of PA and health ${ }^{13}$. Smog influences negatively on people ${ }^{14}$, but it is especially damaging to health when practicing a high intensity of $\mathrm{PA}^{15-17}$. Giorgini et al. ${ }^{13}$ presented a recent review of the cardiovascular implications for health under high levels of contaminated air that showed a great variety of problems associated to the relationship between environmental pollution and PA (e.g., cardiovascular risks, breathing problems, brain oxygenation, blood pressure, etc.). Although some recent studies show that exercising in a polluted environmental could not be absolutely damaging to health ${ }^{18,19}$, their results have been obtained in moderated levels of pollution, not in severe conditions.

The fact that the number of cities with smog problems in all over the world is increasing [e.g., Madrid, Spain; Los Angeles, USA; Beijing, China; or Santiago, Chile $]^{20}$, turns this problem into a serious issue that researchers and professionals belonging to health care need to take into account.
The World Health Organization (WHO) $)^{21}$ and others agencies such as the United States Environmental Protection Agency ${ }^{22}$ have established standards as criteria air pollutants [parts per million (ppm) by volume for gases, such as Carbon Monoxide, Nitrogen Dioxide, Ozone, or Sulfure Dioxide; and micrograms per cubic meter of air $\left(\mu \mathrm{g} / \mathrm{m}^{3}\right)$ for particles pollution $(\mathrm{PM})$, which are divided into $\mathrm{PM}_{2.5}$ and $\mathrm{PM}_{10}$ depending on the diameter of the particles that are referred to $(<$ $2.5 \mu \mathrm{m}$, or $>2.5$ and $<10 \mu \mathrm{m}$, respectively)]. The more common measure of air pollution is the mean annual concentration of fine suspended particles $\left(\mathrm{PM}_{2.5}\right.$ and $\left.\mathrm{PM}_{10}\right)$, due to that these particles penetrate deeply into the respiratory tract and consequently constitute as an important health risk indicator, causing an increment of mortality from respiratory infections and diseases, lung cancer, and selected cardiovascular diseases. For instance, previous meta-analyses have detected the increase of mortality of around $0.5 \%$ for each $10 \mu \mathrm{g} / \mathrm{m}^{3}$ increment in the daily concentration of $\mathrm{PM}_{10}^{23,24}$. The WHO guideline values for mean annual concentration of PM are $20 \mu \mathrm{g} / \mathrm{m}^{3}$ and $10 \mu \mathrm{g} / \mathrm{m}^{3}$ for $\mathrm{PM}_{10}$ and $\mathrm{PM}_{2.5}$, respectively, and the 24 hour average measurement of PM are $50 \mu \mathrm{g} / \mathrm{m}^{3}$ and $25 \mu \mathrm{g} / \mathrm{m}^{3}$ for $\mathrm{PM}_{10}$ and $\mathrm{PM}_{2.5}$, respectively ${ }^{21}$.

Latin American countries, and Chile in particular, are especially affected by air pollution. In fact, Santiago de Chile is considered one of the most highly contaminated cities of Latin America according to the Ambient Air Pollution Database, with an annual mean of $64 \mu \mathrm{g} / \mathrm{m}^{3}$ of $\mathrm{PM}_{10}$ and $29 \mu \mathrm{g} / \mathrm{m}^{3}$ of $\mathrm{PM}_{2.5}$, measured in $2014^{20}$. The Government of Chile has established their own recommendations according to the index of air quality referring to PM by volume [Índice de Calidad del Aire Referido a Partículas (ICAP, in Spanish)], determining different levels of air quality for people in particular days (peaks of pollution measured in 24 hours): good (ICAP $=0-99$ of $\left.\mathrm{PM}_{10}\right)$; mediocre (ICAP = 100-199 of $\left.\mathrm{PM}_{10}\right)$; alert (ICAP $=200-299)$; pre-emergency (ICAP = 300-499 of $\mathrm{PM}_{10}$ ); and emergency (ICAP > 500 of $\mathrm{PM}_{10}$ ). Among other recommendations regarding the correct use of energy sources for alert, pre-emergency, and emergency days [highly contaminated air (HCA) days, from now on], the suppression of physical or sport outdoor activities are also recommended to the population, and even the suppression of the physical education classes in school centers ${ }^{25}$. Most of the authors coincided in recommendation of the diminution of the habitual PA on HCA days as 
a preventive health measure ${ }^{26,27}$. However, unfortunately to our knowledge there are no studies that measure the PA performed (in the complete day, school time, or out of school time) on HCA days, in order to verify the population awareness regarding the consequences of air pollution on individuals' health.

Given the above commented repercussions and recommendations for global people under HCA conditions, and the fact that Santiago de Chile is one of the most affected cities by this problem in Latin American countries, it seems interesting to know if the public and scientists recommendations regarding the decrease of $\mathrm{PA}$ have had effect on the habitual PA of the population, mainly centered in school ages, and with the objective-measure of this PA. Consequently, the purpose of the present study was to compare the accelerometer-measured PA and sedentary behavior during the whole day, in-school time, out-of-school time, and school breaks between HCA days and non-HCA days in adolescents from Santiago of Chile.

\section{Methods}

\section{Participants}

A sample of 19 Chilean adolescents in the eighth grade, 11 boys and 8 girls, of basic education level municipalized schools agreed to participate in the present study and met the inclusion criteria. All the adolescents belonged to the district called Nuñoa (Santiago de Chile, Chile). The inclusion criteria were: (a) being enrolled in the eighth grade of any selected school; (b) being free of any health disorder which will make them unable to undergo PA; (c) wearing the accelerometer during at least one HCA day and two nonHCA days of the five monitored weekdays, and (d) presenting the corresponding signed consent by their parents or legal guardians. The exclusion criterion was not having at least one HCA day and two non-HCA days within the minimum valid wear time of any analyzed period. The protocol of the present study was approved by the Ethical Committee of the University of Granada.

\section{Measures}

Objectively-measured PA and sedentary behavior was assessed by a GT3X accelerometer (ActiGraph, LLC, Pensacola, FL, USA). The GT3X accelerometer is a compact $(3.8 \times 3.7 \times$
$1.8 \mathrm{~cm}$ ), lightweight (27 g), and triaxial monitor designed to record time varying accelerations ranging in magnitudes from approximately 0.05 to $2.50 \mathrm{Gs}$. The accelerometer output is digitized by a 12-bit analog-to-digital converter at rates of 30-100 Hz, with a frequency range limit between $0.25-2.5 \mathrm{~Hz}$. The filtered signal is then rectified and integrated over a user-specified time interval known as epoch. At the end of each epoch, the summed value known as "activity count" or counts is stored in memory and the integrator is reset. The counts obtained in a particular epoch are proportional to the intensity of the PA during the measured period ${ }^{28}$.

After adolescents' PA and sedentary behavior was monitored, data were downloaded and analyzed using the ActiLife Lifestyle Monitoring System Software version 6.13.2. In-school time, outof-school time and school break periods were registered according to the schools schedules. Out-of-school was registered from the end of the school time to the end of the day (i.e., 23:59 h). A minimum wear time of $600 \mathrm{~min}$ for the whole day $^{29}, 300 \mathrm{~min}$ for in-school time, $300 \mathrm{~min}$ for out-of-school time, and $85 \mathrm{~min}$ (i.e., 100\%) for school breaks were set. Non-wear periods were defined as default as a minimum length of $60 \mathrm{~min}$ of consecutive zero-count epochs with up to 2 min spike tolerance ${ }^{30}$. Counts per minute recorded in the vertical axis, also known as $y$-axis or axis 1 , were calculated. Step counts per minute were assessed by within-instrument processing of the number of cycles in the accelerometer signal or cycle counts. To determine the percentage of time engaged in sedentary, light and moderate-to-vigorous PA, Evenson's cut-off points were used ${ }^{28,31}$. Moderate-to-vigorous PA bouts variables were calculated as was default with a minimum length of $10 \mathrm{~min}$ and a drop time of $2 \mathrm{~min}^{2}$. Sedentary variables were calculated as was default with a minimum length of $10 \mathrm{~min}$ and counts levels of $<100^{28,32}$. ActiGraph accelerometer-measured PA and sedentary behavior has shown a high reliability and validity among adolescents ${ }^{28,33}$.

\section{Procedure}

The principals and the physical education teachers of 10 basic education level municipalized schools belonging to the Community of Nuñoa (Santiago de Chile, Chile) were contacted by a researcher. They were informed about the project and the permission to conduct the study was requested. After approvals of four schools were obtained, eighth-grade students and their 
legal guardians were fully informed about all the features of the study (i.e., a thorough description of the methods, potential risks, expected benefits, etc.; based on Thomas, Nelson, and Silverman guidelines ${ }^{34}$ ), and written informed consent was obtained from all the participants' legal guardians to take part in the study.

Data collection was done during summertime due to it being the more probable period of weather influences in the HCA conditions. The limitation of the number of accelerometers available for this research (20), made the researchers have to collect data week by week during the months of July and August of 2015 in order to capture the habitual and particular PA of nonHCA days and some possible HCA days from a sample of Chilean adolescents. During a physical education class a trained researcher fitted the accelerometers on the right hip of all the participants by using an elastic waistband. Participants were instructed to wear the accelerometer for eight consecutive days (from July $30^{\text {th }}$ to $7^{\text {th }}$ August). Participants were asked to wear the accelerometer from waking to bedtime, to take the accelerometer off only when engaged in aquatic activities or taking a shower, and to maintain their normal PA habits. To avoid biases because of participants' reactivity, data of the first three days were considered as familiarization days and they were not used for statistical analyses.

The third and fourth of August of 2015 were declared as "alert" and "pre-emergency environmental" days in the city of Santiago, respectively. From the initial sample of 156 students who participated in the present study, 19 adolescents of the same school wore the accelerometer during one-to-two of the HCA days of their five monitored weekdays. Adolescents were in the school between 8:00 h to 15:15 h. They had three school breaks: 9:30-9:50 h, 11:10-11:30 $\mathrm{h}$ and 13:0013:45 h. Out-of-school time was registered between 15:15h to $23: 59 \mathrm{~h}$.

\section{Statistical analyses}

Descriptive statistics for the general characteristics, PA and sedentary behavior variables of the studied participants were calculated. The Wilcoxon test was used to examine the differences on PA and sedentary behavior during the whole day, in-school time, out-of-school time and school breaks between HCA and non-HCA days. To avoid potential bias due to differences in the length of total valid wear time of any analyzed period, wear time-based standardized scores were used. The $r$ effect size was calculated to examine the magnitude of the difference ${ }^{35}$. All statistical analyses were performed using the SPSS Version 21.0 for Windows $\left(\right.$ IBM $^{\circledR}$ SPSS $^{\circledR}$ Statistics). The statistical significance level was set at $p<0.05$.

\section{Results}

\section{General characteristics}

From the initial sample of 19 adolescents who were included in the present study, finally 15 participants ( 8 boys and 7 girls) were included in the statistical analyses (i.e., four adolescents were eliminated due to meeting the exclusion criterion). The general characteristics of the analyzed participants are the following (mean \pm standard deviation):age $=13.40 \pm 0.83$ years; body mass $=$ $57.67 \pm 8.22 \mathrm{~kg}$; body height $=1.59 \pm 0.07 \mathrm{~m}$; and body mass index $=22.64 \pm 3.14 \mathrm{~kg} / \mathrm{m}^{2}$.

\section{Whole day}

Table 1 shows descriptive statistics (median and interquartile range) and Wilcoxon test results for the comparison of adolescents' accelerometer-measured PA and sedentary behavior during the whole day between HCA and nonHCA days. The Wilcoxon test results showed statistically significant higher values of vertical axis and steps on HCA days than on non-HCA days $(p<0.05)$. However, statistically significant differences between HCA and non-HCA days for any of the other PA or sedentary behavior variables were not found $(p>0.05)$.

\section{In-school time and school breaks}

Tables 2-3 show descriptive statistics (median and interquartile range) and Wilcoxon test results for the comparison of adolescents' accelerometer-measured PA and sedentary behavior during in-school time and school breaks between HCA and non-HCA days. The Wilcoxon test results did not show any statistically significant difference on PA and sedentary behavior variables between HCA and non-HCA days ( $p>0.05)$.

\section{Out-of-school time}

Table 4 shows descriptive statistics (median and interquartile range) and Wilcoxon test results for the comparison of adolescents' ac- 
Table 1. Comparison of adolescents' accelerometer-measured physical activity and sedentary behavior during the whole day between highly and non-highly contaminated air days $(\mathrm{n}=15)$

\begin{tabular}{|c|c|c|c|c|c|}
\hline & \multirow{2}{*}{$\begin{array}{l}\text { HCA days } \\
\mathbf{M}\left(\mathbf{Q}_{1}-\mathbf{Q}_{3}\right)\end{array}$} & \multirow{2}{*}{$\begin{array}{c}\text { Non-HCA days } \\
M\left(\mathbf{Q}_{1}-\mathbf{Q}_{3}\right) \\
\end{array}$} & \multicolumn{2}{|c|}{$\begin{array}{c}\text { Wilcoxon } \\
\text { test }\end{array}$} & \multirow{2}{*}{$\begin{array}{c}\text { ES } \\
\mathbf{r} \\
\end{array}$} \\
\hline & & & $\mathrm{Z}$ & $\mathbf{p}$ & \\
\hline \multicolumn{6}{|l|}{ Physical activity } \\
\hline Vertical axis (counts/ min) & $265.95(198.80-382.70)$ & $240.87(155.10-355.83)$ & 1.988 & 0.047 & 0.36 \\
\hline Steps (steps/ min) & $7.90(6.60-12.50)$ & $7.23(5.75-10.40)$ & 2.500 & 0.012 & 0.46 \\
\hline Light $(\%)$ & $33.12(24.08-36.51)$ & $29.39(24.12-33.63)$ & 1.533 & 0.125 & 0.28 \\
\hline Moderate-to-vigorous (\%) & $2.16(1.05-4.47)$ & $2.19(0.91-4.31)$ & 1.136 & 0.256 & 0.21 \\
\hline Bouts in MVPA (bouts/ h) & $0.03(0.00-0.11)$ & $0.04(0.00-0.20)$ & 0.471 & 0.638 & 0.09 \\
\hline Total time in MVPA bouts ( $\mathrm{min} / \mathrm{h}$ ) & $0.30(0.00-1.86)$ & $0.39(0.00-2.53)$ & 0.078 & 0.937 & 0.01 \\
\hline Total counts in MVPA bouts (counts/ h) & $873.01(0.00-6078.17)$ & $985.56(0.00-7527.07)$ & 0.392 & 0.695 & 0.07 \\
\hline \multicolumn{6}{|l|}{ Sedentary behavior } \\
\hline Sedentary $(\%)^{\mathrm{a}}$ & $63.08(59.36-73.32)$ & $68.43(65.46-75.21)$ & 1.761 & 0.078 & 0.32 \\
\hline Sedentary bouts (bouts/h) & $1.00(0.94-1.26)$ & $1.12(1.05-1.30)$ & 1.363 & 0.173 & 0.25 \\
\hline Total time in sedentary bouts $(\mathrm{min} / \mathrm{h})$ & $23.01(18.93-28.80)$ & $28.16(22.70-31.67)$ & 0.852 & 0.394 & 0.16 \\
\hline
\end{tabular}

Table 2. Comparison of adolescents' accelerometer-measured physical activity and sedentary behavior during in-school time between highly and non-highly contaminated air days $(n=15)$

\begin{tabular}{|c|c|c|c|c|c|}
\hline & \multirow{2}{*}{$\begin{array}{l}\text { HCA days } \\
M\left(Q_{1}-Q_{3}\right) \\
\end{array}$} & \multirow{2}{*}{$\begin{array}{c}\text { Non-HCA days } \\
\mathbf{M}\left(\mathbf{Q}_{1}-\mathbf{Q}_{3}\right) \\
\end{array}$} & \multicolumn{2}{|c|}{$\begin{array}{c}\text { Wilcoxon } \\
\text { test }\end{array}$} & \multirow{2}{*}{$\begin{array}{c}\text { ES } \\
\mathbf{r} \\
\end{array}$} \\
\hline & & & $\mathrm{Z}$ & p & \\
\hline \multicolumn{6}{|l|}{ Physical activity } \\
\hline Vertical axis (counts/ min) & $242.65(157.80-473.40)$ & $266.95(208.25-395.27)$ & 0.625 & 0.532 & 0.11 \\
\hline Steps (steps/ min) & $8.45(5.55-13.60)$ & $8.60(6.67-12.70)$ & 0.251 & 0.802 & 0.05 \\
\hline Light $(\%)$ & $34.83(26.21-39.08)$ & $33.03(25.05-38.35)$ & 0.170 & 0.865 & 0.03 \\
\hline Moderate-to-vigorous (\%) & $1.61(0.23-6.56)$ & $2.26(1.00-4.98)$ & 1.221 & 0.222 & 0.22 \\
\hline Bouts in MVPA (bouts/ h) & $0.00(0.00-0.14)$ & $0.00(0.00-0.09)$ & 0.700 & 0.484 & 0.13 \\
\hline Total time in MVPA bouts ( $\mathrm{min} / \mathrm{h}$ ) & $0.00(0.00-2.07)$ & $0.00(0.00-1.02)$ & 0.280 & 0.779 & 0.05 \\
\hline $\begin{array}{l}\text { Total counts in MVPA bouts } \\
\text { (counts/ h) }\end{array}$ & $0.00(0.00-5668.97)$ & $0.00(0.00-2858.34)$ & 0.280 & 0.779 & 0.05 \\
\hline \multicolumn{6}{|l|}{ Sedentary behavior } \\
\hline Sedentary $(\%)^{\mathrm{a}}$ & $64.14(55.52-72.65)$ & $64.49(55.69-69.81)$ & 0.227 & 0.820 & 0.04 \\
\hline Sedentary bouts (bouts/h) & $1.10(0.97-1.38)$ & $1.00(0.90-1.29)$ & 1.903 & 0.057 & 0.35 \\
\hline Total time in sedentary bouts $(\mathrm{min} / \mathrm{h})$ & $23.59(16.97-30.83)$ & $23.22(16.31-30.45)$ & 0.170 & 0.865 & 0.03 \\
\hline
\end{tabular}

celerometer-measured PA and sedentary behavior during out-of-school time between HCA and non-HCA days. The Wilcoxon test results showed statistically significant higher values of vertical axis, steps and moderate-to-vigorous PA on HCA days than on non-HCA days $(p<0.05)$. However, for the other PA variables and any sedentary behavior variable statistically significant differences between HCA and non-HCA days were not found $(p>0.05)$.

\section{Discussion}

The aim of the present study was to compare the accelerometer-measured PA and sedentary be- 
Table 3. Comparison of adolescents' accelerometer-measured physical activity and sedentary behavior during school breaks between highly and non-highly contaminated air days $(\mathrm{n}=15)$

\begin{tabular}{|c|c|c|c|c|c|}
\hline & \multirow{2}{*}{$\begin{array}{l}\text { HCA days } \\
M\left(Q_{1}-Q_{3}\right)\end{array}$} & \multirow{2}{*}{$\begin{array}{c}\text { Non-HCA days } \\
M\left(Q_{1}-Q_{3}\right)\end{array}$} & \multicolumn{2}{|c|}{$\begin{array}{l}\text { Wilcoxon } \\
\text { test }\end{array}$} & \multirow{2}{*}{$\begin{array}{c}\text { ES } \\
\mathbf{r} \\
\end{array}$} \\
\hline & & & $\mathbf{Z}$ & $\mathrm{p}$ & \\
\hline \multicolumn{6}{|l|}{ Physical activity } \\
\hline Vertical axis (counts/ min) & $452.20(274.40-1323.30)$ & $517.83(352.80-1227.00)$ & 0.398 & 0.691 & 0.07 \\
\hline Steps (steps/ min) & $15.10(10.20-41.65)$ & $17.87(13.50-32.03)$ & 0.511 & 0.609 & 0.09 \\
\hline Light $(\%)$ & $54.71(43.61-70.35)$ & $53.33(45.88-63.14)$ & 0.966 & 0.334 & 0.18 \\
\hline Moderate-to-vigorous (\%) & $1.77(0.00-28.24)$ & $3.14(0.59-16.47)$ & 0.941 & 0.347 & 0.17 \\
\hline Bouts in MVPA (bouts/ h) & $0.00(0.00-0.71)$ & $0.00(0.00-0.35)$ & 0.405 & 0.686 & 0.07 \\
\hline Total time in MVPA bouts $(\mathrm{min} / \mathrm{h})$ & $0.00(0.00-9.88)$ & $0.00(0.00-3.88)$ & 0.405 & 0.686 & 0.07 \\
\hline $\begin{array}{l}\text { Total counts in MVPA bouts } \\
\text { (counts/ h) }\end{array}$ & $0.00(0.00-27524.47)$ & $0.00(0.00-10571.65)$ & 0.405 & 0.686 & 0.07 \\
\hline \multicolumn{6}{|l|}{ Sedentary behavior } \\
\hline Sedentary $(\%)^{\mathrm{a}}$ & $29.07(15.29-55.23)$ & $40.39(20.39-50.00)$ & 1.023 & 0.307 & 0.19 \\
\hline Sedentary bouts (bouts/ h) & $0.00(0.00-0.35)$ & $0.35(0.18-0.70)$ & 1.453 & 0.146 & 0.27 \\
\hline $\begin{array}{l}\text { Total time in sedentary bouts } \\
(\mathrm{min} / \mathrm{h})\end{array}$ & $0.00(0.00-4.94)$ & $3.77(2.35-8.02)$ & 1.804 & 0.071 & 0.33 \\
\hline
\end{tabular}

Table 4. Comparison of adolescents' accelerometer-measured physical activity and sedentary behavior during out-of-school time between highly and non-highly contaminated air days $(\mathrm{n}=14)$

\begin{tabular}{|c|c|c|c|c|c|}
\hline & \multirow{2}{*}{$\begin{array}{l}\text { HCA days } \\
M\left(Q_{1}-Q_{3}\right)\end{array}$} & \multirow{2}{*}{$\begin{array}{c}\text { Non-HCA days } \\
M\left(\mathbf{Q}_{1}-\mathbf{Q}_{3}\right) \\
\end{array}$} & \multicolumn{2}{|c|}{$\begin{array}{c}\text { Wilcoxon } \\
\text { test }\end{array}$} & \multirow{2}{*}{$\begin{array}{c}\text { ES } \\
\mathbf{r}\end{array}$} \\
\hline & & & $\mathrm{Z}$ & $\mathbf{p}$ & \\
\hline \multicolumn{6}{|l|}{ Physical activity } \\
\hline Vertical axis (counts/ min) & $381.45(250.39-456.79)$ & $264.65(206.92-418.10)$ & 2.040 & 0.041 & 0.39 \\
\hline Steps (steps/ min) & $11.65(8.15-13.86)$ & $8.55(5.67-12.64)$ & 2.230 & 0.026 & 0.42 \\
\hline Light $(\%)$ & $39.34(30.17-44.30)$ & $34.93(29.13-37.22)$ & 1.099 & 0.272 & 0.21 \\
\hline Moderate-to-vigorous (\%) & $3.53(1.88-6.91)$ & $1.54(1.02-3.78)$ & 1.977 & 0.048 & 0.37 \\
\hline Bouts in MVPA (bouts/ h) & $0.03(0.00-0.13)$ & $0.02(0.00-0.11)$ & 0.770 & 0.441 & 0.15 \\
\hline Total time in MVPA bouts ( $\mathrm{min} / \mathrm{h}$ ) & $0.36(0.00-1.76)$ & $0.20(0.00-1.30)$ & 0.178 & 0.859 & 0.03 \\
\hline $\begin{array}{l}\text { Total counts in MVPA bouts } \\
\text { (counts/ h) }\end{array}$ & $1030.69(0.00-7652.08)$ & $553.45(0.00-3417.92)$ & 1.125 & 0.260 & 0.21 \\
\hline \multicolumn{6}{|l|}{ Sedentary behavior } \\
\hline Sedentary $(\%)^{\mathrm{a}}$ & $56.30(51.88-66.36)$ & $62.29(59.28-69.85)$ & 1.601 & 0.109 & 0.30 \\
\hline Sedentary bouts (bouts/ h) & $0.77(0.58-1.30)$ & $1.06(0.94-1.20)$ & 1.161 & 0.245 & 0.22 \\
\hline Total time in sedentary bouts $(\mathrm{min} / \mathrm{h}$ ) & $15.88(10.96-27.30)$ & $23.80(21.14-26.36)$ & 1.412 & 0.158 & 0.27 \\
\hline
\end{tabular}

havior during the whole day, in-school time, outof-school time, and school breaks between HCA days and non-HCA days in Chilean adolescents. Regarding the PA performed by the studied sample, the vertical axis and steps per minute for the whole day, and both of these variables together with the percentage of time of moderate-to-vigorous PA levels in the out-of-school time period were higher in HCA days than in non-HCA days. Results for sedentary behavior were similar on HCA and non-HCA days for every period of time analyzed. The expected results according 
to a good understanding of the repercussions to participants' health in this study and the Chilean government's recommendations had been obtaining differences in favor of non-HCA days for PA variables, and in favor of HCA days for the time involved in sedentary behavior (as detected previously in international contexts) $)^{36}$, but surprisingly they were not. These results allow us to conclude, in general, the lack of awareness of the participants in this research regarding the health repercussions commented in the introduction section in relation to the PA performed during air pollution exposure.

The number of steps and the light PA performed by the studied sample provide less significant information in regard to the adolescents' health repercussions. For instance, breathing deeply in order to provide higher ventilation produces higher damage on health than normal breathing, due to the quantity of PM that passes to the lungs. Moreover, breathing through the nose also provides a filter that breathing through the mouth does not, which is an important difference between performing light or moderate-to-vigorous PA in air pollution exposure. Due to this, low intensities of PA do not have the same negative consequences as high intensities preformed in air pollution conditions, though some negative effects have still been detected ${ }^{16}$. For instance, walking for two hours in a HCA area was enough to reduce lung function in an asthmatic sample ${ }^{37}$. Nevertheless, the relationship between PA and health in air pollution exposure is complex, and also depends on the level of contamination of the air breathed. For instance, $\mathrm{Yu}$ et al. $^{38}$ detected that habitual PA of children (8-12 years old) in low-pollution air conditions improved the cardiorespiratory fitness regarding the maximal oxygen uptake, but this finding was not obtained with children living in a high-pollution area. However, the damaging effects of air pollution could be noticed in individuals' health even in lower concentrations of PM by volume of air (e.g., levels of $\mathrm{PM}_{2.5}$ around $10 \mu \mathrm{g} / \mathrm{m}^{3}$ is positively associated with lung cancer $^{39}$ ). Consequently, decreasing the time involved in low intensity of PA if possible (e.g., walk, or any other exercise considered as light PA) could be also recommended to Chilean adolescents in HCA conditions, especially to those who present cardiorespiratory diseases.

In regards to sedentary behavior, perhaps it is the only condition in which its increase is expected on HCA days, as a consequence of the recommendation of decreasing general PA and re- gardless of its negative health repercussions (e.g., increasing the risk of morbidity and mortali$\left.t y^{13,23}\right)$. However, in contrast of this expectation, sedentary behavior values in all time segments of the day between HCA and non-HCA conditions were similar. These results demonstrate that there were no influences on Chilean adolescents' sedentary behavior related to air pollution exposure. Due to the demonstrated negative repercussions to health, it is difficult to recommend the increment of sedentary behavior time as a measure of health prevention on HCA days. In contrast, researchers of this study recommend Chilean adolescents, as much as is possible, to practice PA outside the urban area of the city of Santiago on HCA days (e.g., the Andes chain of mountains close to Santiago allow local people to practice a great variety of sports and PA such as hiking/ trekking; mountain-biking; jogging; climbing; and skiing, although this last option is expensive in general, and more for those from high-income areas of Santiago).

Regarding the different time periods analyzed, the changes detected in the percentage of moderate-to-vigorous PA in the out-of-school time may have influenced on the vertical axis and steps variables for whole day. These three variables were higher on HCA than non-HCA days, as commented above for the general discussion of the results obtained. It is important to denote that out-of-school time is the period that mainly contributes to moderate-to-vigorous PA throughout the day ${ }^{9,40}$, and this level of physiological implication in the performed PA depends only on the will of individuals ${ }^{41}$. Therefore, these results suggest that a great lack of knowledge regarding the consequences on health is attributable to this youth population belonging to Santiago of Chile. Awareness campaigns toward Chilean adolescents are necessary in order to alert this population regarding their damage to health in regard to moderate-to-vigorous PA intensities and the quality of the air they breath during exercise periods.

Regarding the school periods (in-school time and school breaks) there were no statistical differences, but some reflections need to be considered. On one hand, recess or school breaks are periods where the performed PA also depends on the will of the schoolchildren and adolescents ${ }^{41}$, and its importance is increasingly more valued for achieving the daily recommended moderate-to-vigorous $\mathrm{PA}^{42}$. Some students develop PA in a high intensity during this period, perhaps less percentage of students than desirable $e^{9,40,42}$, 
but those students need to be alert of the damage to health consequences if practicing PA in HCA conditions. Teachers and educators in educational settings, and particularly physical education teachers, should have some planned routines to be applied and in order to inform all students about health measures to perform (e.g., to inform in the first theoretical class of the morning about health preventive measures; to hang some information panels and signs on wall halls and in the schoolyard; or to distribute information for parents and families in a website or by mail). Recess or school breaks have also been studied in order to find new proposals for incrementing moderate-to-vigorous PA that could help adolescents living in HCA conditions. For instance, in the study of Erwin et $\mathrm{al}^{43}$, the use of indoor recess dance videos for American children was proposed. Results showed an increase of the PA performed, reaching $68 \%$ of the recess' time involved in PA. Other effective indoor alternatives mentioned in literature during physical education lessons or school recess could be the use of exergames ${ }^{44}$ or jumping rope $^{45}$, for instance. Taking into account that these strategies have been demonstrated as effective in increasing the PA of children and adolescents in indoor conditions, they could be also applied for HCA school contexts. For example, some active games (e.g., Dance Revolution) are considered to be as active as conventional moderate-to-vigorous physical activities ${ }^{46}$.

Finding solutions for out-of-school time is a bit more complex. Analyzing previous research regarding the PA performed in large Latin American urban conglomerations ${ }^{47}$, some factors regarding the built environment could influence the results obtained and the actions that could be proposed. For instance, the neighborhood walkability (composed of a mix of population density, intersection density, and land use) influences the PA performed by population who live in particular geographical areas ${ }^{48}$. Contextual factors such as urban safety ${ }^{47}$; recreational spaces ${ }^{49}$; parks ${ }^{50}$; indoor sports facilities (although the pollution concentrations also appear in some fitness centers $)^{51}$; public transportation and general public services are linked to PA patterns ${ }^{47}$, and to air pollution concentrations ${ }^{52}$. In this line, the four types of city blocks classified by Hankey et al. ${ }^{48}$ according to air pollution level and the rate of active travel could also open new perspectives for planning solutions in highly populated areas: "sweet-spot" (high active travel and low particulate concentration), "sour-spot" (low active travel, high particulate concentration), "active \& exposed" (high active travel and high particulate concentration), and "inactive \& clean" (low active travel and low particulate concentration). Large urban Latin American cities, such as Santiago of Chile, should be analyzed by the blocks' characteristics in order to apply appropriate solutions. Most of the time, the complex problem of the PA performed in HCA is not attributable to particular individuals (e.g., physical education teachers, or adolescents' behavior), but a lack of general forecast and planning.

According to the above comments promoting active living is crucial and requires: a) a strong civil society leadership, which implies urban interventions motivated by explicit discourses in favor of PA promotion ${ }^{47}$; and b) a deep evaluation of benefits (PA) and hazards (air pollution) by public health officials and urban planners in order to promote healthy cities (e.g., moving bicycle routes away from high-traffic roads $)^{48}$. Therefore, to solve the lack of PA or to promote safe PA in HCA among adolescents entails offering good opportunities to practice (development of special programs through indoor sports facilities, and reducing air pollutants of large urban areas through regulation of curbing sprawl, public transportation, and land use, among other factors).

To our knowledge, this is the first study that compares the objectively-measured PA and sedentary behavior between HCA and non-HCA days, which is the most important strength of the present research. Some limitations such as the limited sample, or having more declared pre-emergency, emergency, or alert days by the government would be also interesting in order to register a more stable behavior of participants on HCA days.

Further research studies are encouraged in order to better explain this complex relationship between PA in acute air pollution exposure. It is necessary to verify or compare the present results with a wider sample and in several contexts (cities and countries), sex, ages (earlier and older scholar ages and adults), weekend days, and levels of pollution air areas, as well as to implement and test the effect of intervention programs regarding the awareness of the adolescent population of Santiago of Chile on the PA performed in-school time and out-of-school time. 


\section{Collaborations}

J Viciana worked on the design and final text, D Mayorga-Vega contributed to the data analyses and final text, and M Parra-Saldías worked on the data collection and revised the final manuscript.

\section{Acknowledgments}

Authors want to thank Aliisa Hatten for the English revision of the manuscript

\section{References}

1. Reiner M, Niermann C, Jekauc D, Woll A. Long-term health benefits of physical activity-a systematic review of longitudinal studies. BMC Pub Health 2013; 13:1-9.

2. World Health Organization (WHO). Global Recommendation on Physical Activity for Health. Geneva: WHO; 2010.

3. Cocca A, Liukkonen J, Mayorga-Vega D, Viciana J. Health-related physical activity levels in Spanish youth and young adults. Percept Motor Skills 2014; 118(1):247-260.

4. Le Blanc A, Katzmarzyk P, Barreira T, Broyles S, Chaput J, Church T, Fogelholm M, Harrington DM, Hu G, Kuriyan R, Kurpad A, Lambert EV, Maher C, Maia J, Matsudo V, Olds T, Onywera V, Sarmiento OL, Standage M, Tudor-Locke C, Zhao P1, Tremblay MS, ISCOLE Research Group. Correlates of Total Sedentary Time and Screen Time in 9-11 Year-Old Children around the World: The International Study of Childhood Obesity, Lifestyle and the Environment. PLOS One 2015; 10(6):1-20.

5. Sedentary Behavior Research Network. Letter to the editor: Standardized use of the terms "sedentary" and "sedentary behaviours". Appl Phys Nutr Metab 2012; 37(3):540-542.

6. Carson V, Hunter S, Kuzik N, Gray CE, Poitras V, Chaput JP, Saunders TJ, Katzmarzyk PT, Okely AD, Connor Gorber S, Kho ME, Sampson M, Lee H, Tremblay MS. Systematic review of sedentary behaviour and health indicators in school-aged children and youth: an update. Appl Phys Nutr Metab 2016; 41(6):S240-S265.

7. Ferreira AC, Henrique P, Rossi P. The worldwide prevalence of insufficient physical activity in adolescents; a systematic review. Nutr Hosp 2013; 28(3):575-584.

8. Kretschmann R. Objective measurement of physical activity levels in everyday physical education. Res $Q$ Exerc Sport 2011; 85(1):143.

9. Viciana J, Mayorga-Vega D, Martínez-Baena A. Moderate-to-vigorous physical activity levels in physical education, school recess and after-school time. Influence of gender, age, and weight status. J Phys Act Health 2016; Epub ahead of print 18 July 2016.

10. Centers for Disease Control and Prevention. The Benefits of Physical Activity. [cited 2016 Aug 17]. Available from: http://www.cdc.gov/physicalactivity/everyone/ health

11. World Health Organization (WHO). World Health Organization Step to Health: A European Framework to Promote Physical Activity for Health. 2015 [cited 2016 Aug 17]. Available from: http://www.euro.who. int/_data/assets/pdf_file/0020/101684/E90191.pdf 
23. Cohen AJ, Anderson HR, Ostro B, Pandey KD, Krzyzanowski M, Künzli N, Gutschmidt K, Pope A, Romieu I, Samet JM, Smith K. Mortality impacts of urban air pollution. In: Ezzati M, Lopez AD, Rodgers A, Murray CU, editors. Comparative quantification of health risks: Global and regional burden of disease due to selected major risk factors. Geneva: World Health Organization; 2004. p. 1353-1434.

24. International Oversight Committee. Health effects of outdoor air pollution in developing countries of Asia: a literature review. Boston, MA, Health Effects Institute (Special Report No. 15). 2004 [cited 2016 Sep 15]. Available from: https://www.healtheffects.org/publication/health-effects-outdoor-air-pollution-developing-countries-asia-literature-review

25. Chile. Ministry of Natural Environment and Ministry of Health. Mapa de la calidad del aire de la región metropolitana [Map of air quality of the Metropolitan region]. 2016 [cited 2016 Aug 10]. Available from: http://portal.mma.gob.cl/pronostico-rm/

26. Laumbach R, Meng Q, Kipen $H$. What can individuals do to reduce personal health risks from air pollution? J Thoracic Disease 2015; 7(1):96-107.

27. Lü J, Liang L, Feng Y, Liu Y. Air pollution exposure and physical activity in China: Current knowledge, public health implications, and future research neeeds. Int $J$ Environ Res Pub Health 2015; 12(11):14887-14897.

28. Trost SG, Loprinzi PD, Moore R, Pfeiffer KA. Comparison of accelerometer cut points for predicting activity intensity in youth. Med Sci Sport Exerc 2011; 43(7):1360-1368.

29. Cain KL, Sallis JF, Conway TL, Van Dyck D, Calhoon L. Using accelerometers in youth physical activity studies: A review of methods. J Phys Act Health 2013; 10(3):437-450.

30. Oliver M, Badland HM, Schofield GM, Shepherd J. Identification of accelerometer nonwear time and sedentary behavior. Res Q Exerc Sport 2011; 82(4):779-783.

31. Evenson KR, Catellier DJ, Gill K, Ondrak KS, McMurray RG. Calibration of two objective measures of physical activity for children. J Sport Sci 2008; 26(14):1557-1565.

32. Treuth MS, Schmitz K, Catellier DJ, McMurray RG, Murray DM, Almeida MJ, Going S, Norman JE, Pate R. Defining accelerometer thresholds for activity intensities in adolescent girls. Med Sci Sport Exerc 2004; 36(7):1259-1266.

33. Santos-Lozano A, Santín-Medeiros F, Cardon G, Torres-Luque G, Bailón R, Bergmeir C, Ruiz JR, Lucia A, Garatachea N. Actigraph GT3X: Validation and determination of physical activity intensity cut points. Int $\mathrm{J}$ Sport Med 2013; 34(11):975-982.

34. Thomas JR, Nelson JK, Silverman SJ. Research methods in physical activity (6th ed.). Champaign: Human Kinetics; 2011.

35. Field A. Discovering statistics using SPSS. $3^{\text {th }}$ ed. London, UK: SAGE Publications; 2009.

36. Roberts JD, Voss JD, Knight B. The association of ambient air pollution and physical inactivity in the United States. PLoS ONE 2014; 9(3):e90143.

37. McCreanor J, Cullinan P, Nieuwenhuijsen MJ, Stewart-Evans J, Malliarou E, Jarup L, Harrington R, Svartengren M, Han IK, Ohman-Strickland P, Chung KF, Zhang J. Respiratory effects of exposure to diesel traffic in persons with asthma. New Engl J Med 2007; 357(23):2348-2358.
38. Yu IT, Wong TW, Liu HJ. Impact of air pollution on cardiopulmonary fitness in schoolchildren. J Occup Environ Med 2004; 46(9):946-952.

39. Tomczak A, Miller AB, Weichental SA, To T, Wall C. Long-term exposure to fine particulate matter air pollution and the risk of lung cancer among participants of the Canadian National Breast Screening Study. Int $J$ Cancer 2016; 139(9):1958-1966.

40. Mayorga-Vega D, Viciana J. Differences in physical activity levels in school-based contexts. Influence of gender, age, and body weight status. Kinesiology 2015; 47(2):151-158.

41. Mayorga-Vega D, Viciana J. Adolescents' physical activity in physical education, school recess, and extra-curricular sport by motivational profiles. Percept Motor Skills 2014; 118(3):663-679.

42. Frömel K, Svozil A, Chmelik F, Jakubec L, Groffik D. The role of physical education lessons and recesses in school lifestyle of adolescents. J School Health 2016; 86(2):143-157.

43. Erwin H, Koufoudakis R, Beighle A. Children's physical activity levels during indoor recess dance videos. J School Health 2013; 83(5):322-327.

44. Gao Z, Chen S, Huang C, Stodden DF, Xiang P. Investigating elementary school childrens' daily physical activity and sedentary behavior during weekdays. $J$ Sport Sci 2017; 35(1):99-104.

45. Loucaides CA, Jago R, Charalambous I. Promoting physical activity during school break times: piloting a simple, low cost intervention. Prev Med 2009; 48(4):332-334.

46. Gao Z, Chen S. Are field-based exergames useful in preventing childhood obesity? A systematic review. Obes Rev 2014; 15(8):676-691.

47. Gomez LF, Sarmiento R, Ordóñez MF, Pardo F, Hérik T, Mallarino CH, Miranda JJ, Mosquera J, Parra DC, Reis R, Quistberg A. Urban environment interventions linked to the promotion of physical activity. A mixed methods study applied to the urban context of Latin America. Soc Sci Med 2015; 131:18-30.

48. Hankey S, Lindsey G, Marshall JD. Population-level exposure to particulate air pollution during active travel: planning for low-exposure, health-promoting cities. Environ Health Perspect 2017; 125(4):527-534.

49. Hino AA, Reis RS, Sarmiento OL, Parra DC, Brownson RC. The built environment and recreational physical activity among adults in Curitiba, Brazil. Prev Med 2011; 52(6):419-422.

50. Parra DC, McKenzie TL, Ribeiro IC, Ferreira Hino AA, Dreisinger M, Coniglio K, Simoes EJ. Assessing physical activity in public parks in Brazil using systematic observation. Am J Public Health 2010; 100(8):1420-1426.

51. Ramos CA, Wolterbeek HT, Almeida SM. Exposure to indoor air pollutants during physical activity in fitness centers. Build Environ 2014; 82:349-360.

52. Hankey S, Marshall JD, Brauer M. Impacts of the built environment: within-urban variability in physical inactivity, air pollution, and ischemic heart disease mortality. Environ Health Perspect 2012; 120(2):247-253.

Artigo apresentado em 28/10/2016

Aprovado em 19/10/2017

Versão final apresentada em 21/10/2017 